\title{
Cold agglutinin disease following SARS-CoV-2 and Mycoplasma pneumoniae co-infections
}

Chatphatai Moonla ${ }^{1}$, Phandee Watanaboonyongcharoen ${ }^{1}$, Gompol Suwanpimolkul ${ }^{1}$, Leilani Paitoonpong$^{1}$, Watsamon Jantarabenjakul ${ }^{1}$, Chantiya Chanswangphuwana ${ }^{1}$, Chantana Polprasert $^{1}$, Ponlapat Rojnuckarin ${ }^{1}$, and Opass Putcharoen ${ }^{1}$

${ }^{1}$ Chulalongkorn University Faculty of Medicine

May 13, 2020

\begin{abstract}
During coronavirus disease 2019 (COVID-19) pandemic, coinfections with other viral infections are not uncommon, but concomitant atypical bacteria are rare. Herein, we describe a young female COVID-19 patient who developed acute cold agglutinin disease secondary to Mycoplasma pneumoniae. Using an azithromycin-containing COVID-19 therapeutic regimen, both pneumonia and anemia resolved uneventfully.
\end{abstract}

\section{Hosted file}

Clin_Case_Rep_Manuscript.doc available at https://authorea.com/users/321381/articles/450668cold-agglutinin-disease-following-sars-cov-2-and-mycoplasma-pneumoniae-co-infections

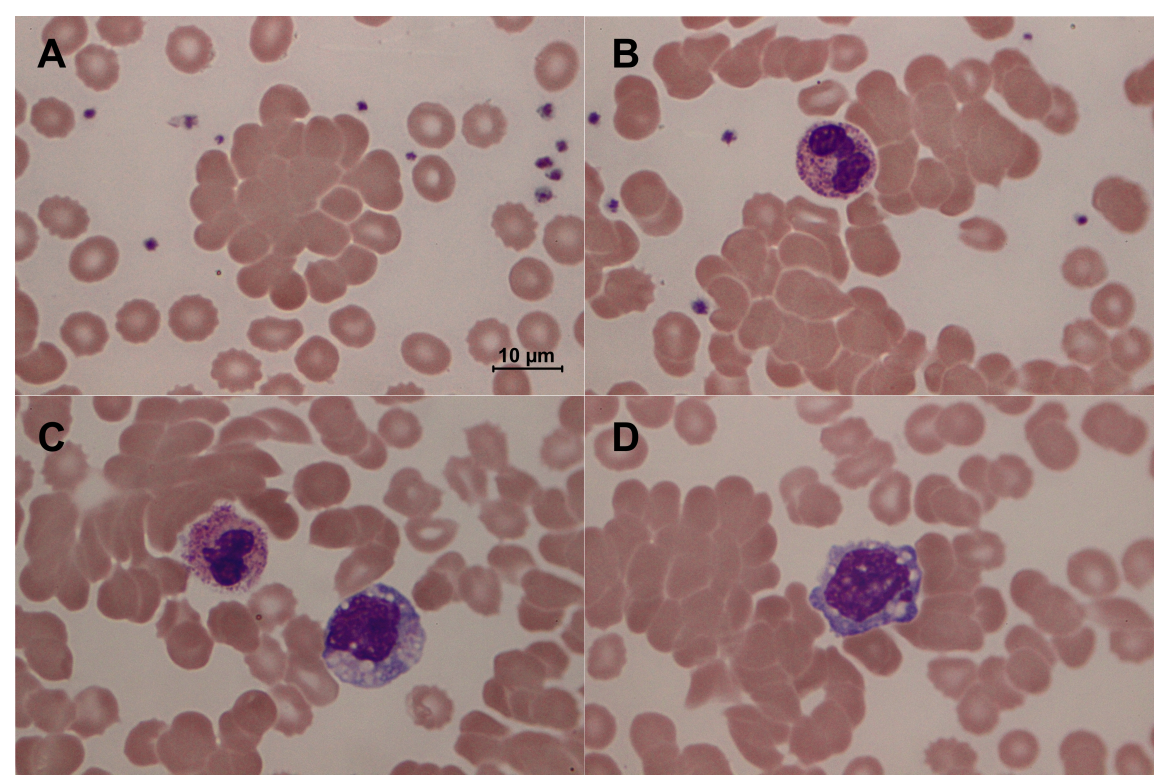

